\title{
Spotlight on the British Dental Conference and Dentistry Show
}

This year's first combined British Dental Conference and Dentistry Show will take place on 18-19 May 2018 at Birmingham NEC. Visit www.thedentistryshow.co.uk and www.bda.org/conference.

\section{The case for good sugars}

Tim Ives will argue the case for 'good sugars' in his Hygienist \& Therapist Symposium session 'Sweet offender versus sweet pretender: utilising sugars to treat and prevent disease.

\section{Dental nurses and dental photography}

Diane Rochford will speak on the benefits of dental photography for dental nurses in the Dental Nurses Forum.

\section{BDA Theatre}

The BDA Theatre will have an exceptional speaker line-up including: Didier Dietschi, Niek Opdam, Charlotte Stilwell, Bhupinder Dawett, Koray Feran, Claire Field and Tidu Mankoo. Topics will include treating tooth wear; ethical restorative strategies; care for patients who have had dental implants placed by other clinicians, and much more.

\section{Dental and systemic health}

Melonie Prebble and Victoria Wilson will be exploring the links between oral and systemic health in the Hygienist \& Therapist Symposium.

\section{British Dental Conference \& dentistru
sП口س /IIII}

\section{Understanding behavioural change}

Dentist Ben Atkins will be presenting on patient understanding and behavioural change at the Hygienist \& Therapist Symposium, and the importance of patient trial outcomes.

\section{Enhancing implant treatment outcomes} Dr Paolo Nardinocchi from Italy will be discussing the topic of soft and hard tissue remodelling around an implant and introducing a new trans-mucosal neck design in the ADI Implant Theatre.

\section{Dental medical emergencies}

Helen Watson and Lynn Fox - owners and instructors from Orchard Training Services and ResusPlus Training respectively - will each present sessions on dental medical emergencies in the Core CPD Theatre.

\section{Simple endodontic excellence}

In his presentation entitled 'Make it simple, follow the StyleItaliano endodontics philosophy', Riccardo Tonini will explain the StyleItaliano mission of setting excellent standards while simplifying protocols to make endodontic treatment feasible, repeatable and more teachable. He will be speaking in the Special Interest Theatre.

Improving aesthetic outcomes Dominic Hassall is presenting a session entitled 'Creating the perfect smile' in the BACD Aesthetic and Digital Dentist Theatre. He will discuss strategies to identify the precise aesthetic concerns of a patient, and how realistic and achievable these concerns are.

\section{Sustainable aspirator tubes}

Swedish based manufacturer Orsing has introduced two new aspirator tubes in the Hygovac range. Hygovac Bio is an aspirator tube made entirely of sustainable bio based polyethylene and will come in two new sizes, providing an opportunity to choose a length which suits the treatment.

The development of the new Hygovac Bio focused mainly on the thought of saving and reducing the use of fossil resources and the level of greenhouse gas emissions. Hygovac Bio is an aspirator tube made of renewable resources. It is built up by absorbed $\mathrm{CO}_{2}$ from the atmosphere and recyclable in existing waste streams. Simple and ECO-logical.

Hygovac Bio is available in two new sizes; the aspirator tube still has the same diameter and provides the same suction as previous Hygovac products. The shorter version is $95 \mathrm{~mm}$ and provides the option to choose the right length for each specific

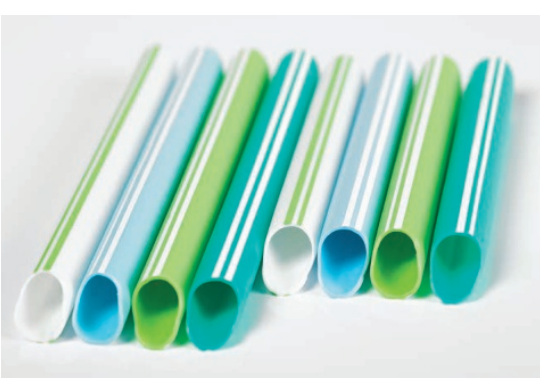

treatment. It is ideal for hygienists and will give an easier access when working without assistance. Less material is used producing Hygovac Bio and less storage space is required in the clinic.

Besides the new Hygovac Bio the Hygovac range of aspirator tubes consists of Hygovac and the ventilated Hygovac Vent. The dual tips, with one traditional $45^{\circ}$ end and one S-shaped, give the freedom of choice and increased patient comfort.

Hygovac Bio are available for purchase from this April. For more information contact your Area Sales Manager or go to: www.orsing.se/news.

\section{The first biotech dental product}

Get your patients involved in National Smile Month with the new CALCIVIS imaging system. It is the first biotech dental product in the world!

The CALCIVIS device applies a luminescent photoprotein to tooth surfaces, which detects free calcium ions and delivers an easy to understand, visual map of active demineralisation at the chair side.

This unique early detection system enables practitioners to plan and deliver preventive measures at the earliest, most reversible stages. They can present customised information to patients and help individuals to comprehend their risk of dental caries.

CALCIVIS is the first and most advanced visual aid of its kind, supporting the preventive dentistry approach and engaging patients with fascinating, glowing, live images to encourage them to improve their oral health.

To interest and motivate your patients for National Smile Month and beyond, contact CALCIVIS now. Visit www.CALCIVIS.com or call 01316585152. 